services to more systematically target social needs and to share power through partnership working may reduce the mistrust that many with psychosis feel when entering services and in turn reduce persistent inequalities across ethnic groups.

\section{BUILDING TRUST IN CLINICIAN-DETAINEE INTERACTIONS: THE ROLE OF A BOUNDARY OBJECT}

P Makela. London School of Hygiene and Tropical Medicine, UK

\subsection{6/bmjopen-2021-QHRN.51}

Background Detainees in Immigration Removal Centres (IRC) report distrust in interactions with staff and Home Office officials. ${ }^{1}$ Clinicians volunteering with NGOs offer independent medical assessments and write medico-legal reports to support detainees' asylum claims. Outcomes could be impacted if insufficient trust is established, or if distrust develops, when discussing traumatic experiences that can recreate positions of powerlessness and vulnerability. The complex dynamics of trust-building with detainees have seldom been explored in IRC contexts, which typically preclude researchers' direct access.

Aim To identify processes that enable trust-building in clinician-detainee interactions in an IRC in England, using the qualitative tool of autoethnographic reflection.

Methods I explored my own practice as a volunteer physician undertaking clinical assessments with detainees over a two-year period, through reflexive autoethnography. I used the conceptual lens of boundary-spanning work ${ }^{2}$ to explore trust-enabling processes within the particular social context of my interactions with detainees.

Results As detainees shared emotional accounts of traumatic experiences, collaborative navigation of uncertainties replaced the traditional 'history-taking' performative of clinician-led interactions. The intended transformation of a narrative into a medico-legal report allowed an intermediary platform between detainees' telling of individual experiences and my re-telling in the form of the 'expert evidence' required for asylum claims. Conclusion The objective of generating content for a detainee's medico-legal report differs from the 'usual' circumstances of a medical assessment. Reciprocal processes of narration can rechannel power asymmetries inherent in the interaction, coconstructing some form of agency. Boundary objects between forms of knowledge might offer a platform for building trust in precarious clinical interactions.

\section{REFERENCES}

1. Kellezi $B$, et al. Understanding and coping with immigration detention: Social identity as cure and curse. Eur J Soc Psychol 2019;49:333-51.

2. Long $\mathrm{JC}$, et al. Bridges, brokers and boundary spanners in collaborative networks: a systematic review. BMC Health Serv Res 2013;13:158.

\section{Day 2: Friday 19th March $-14.50-15.50$}

\section{TRUST AFTER AVOIDABLE HARM IN MATERNITY CARE: THE POSSIBILITIES OF ETHICAL AFFORDANCE}

${ }^{1} \mathrm{M}$ Adams*, 1J Sandall, ' J Hartley, ${ }^{2} \mathrm{R}$ ledema. 'Department of Women and Children's Health, King's College, London, UK; ${ }^{2}$ Centre for Team-based Practice and Learning, King's College London

10.1136/bmjopen-2021-QHRN.52
Background After incidents of harm in healthcare, trust in systems and in individuals is at risk. Most harmed families seek open discussion, information and empathy. When clinicians seek to provide this, they envisage risk of harm to themselves and reputations, professional investigation or litigation.

Aims To examine: (a) family expectations of communication following serious incidents and communication constraints felt by clinicians; (b) how some clinicians manage this work; (c) the impact of extensive NHS initiatives to support this work.

Methods Thematic analysis of over 40 in-depth interviews with maternity staff and service-users. ${ }^{1}$

Findings We identify three dimensions of actual incident management events described by clinicians. These are: (1) apology; (2) information sharing; and (3) ongoing relationships. We develop Keane's[2](2016) concept of 'ethical affordance' to understand how clinicians make situated judgements and negotiations of risk to themselves and their colleagues. Affordance involves the open-ended, anticipatory and opportunistic reflective work involved in everyday ethical practise. Contractual and relational aspects of communication with families are negotiated in this way.

Overall, however, these practices are constrained by the contradiction between healthcare policies, promoting openness and trust, and primary legislation, encouraging suspicion. This constraint is felt most acutely when staff are mistrustful of their own organisation and where responsibility for incidents is often individualised.

Conclusion Support of harmed families requires complex skills, including ethical affordance. Considerable investments in highlevel safety improvement has effect only in those services where clinicians feel safe and skills can be developed.

\section{REFERENCES}

1. Our information is drawn from one data set collected as part of Phase $1 \mathrm{~b}$ of the NIHR HS\&DR DISCERN study. This study is a realist analysis of how the disclosure and discussion of harm with women and families in maternity care can be strengthened.

2. Keane W. 2016. Ethical Life: Its Natural and Social Histories. Princeton University Press.

\section{GENDER-BASED STIGMA AND ACCESS TO CARE: INTERSECTING PERSPECTIVES BETWEEN CAREGIVERS AND MEN WHO HAVE SEX WITH MEN IN SENEGAL}

${ }^{1} \mathrm{AG}$ Ndione, ${ }^{2} \mathrm{~F}$ Procureur, ${ }^{2} \mathrm{~A}$ Lepine, ${ }^{3} \mathrm{NN}$ Senne, ${ }^{4} \mathrm{CT}$ Ndour. ${ }^{1} / R D$, Senegal; ${ }^{2}$ University College London, UK; ${ }^{3}$ Paris Saclay, France; ${ }^{4}$ Ministry of Health, Senegal

10.1136/bmjopen-2021-QHRN.53

Context Men who have sex with men (MSM) in Senegal face a challenging socio-legal context, marked by homophobia and the illegality of homosexuality. In addition, HIV prevalence among MSM is $27.6 \%, 46$ times greater than the one in the general population.

Methods This article describes the caregiver/MSM relationship and analyses its effects on access to healthcare by MSM. The data used are from a field survey based on observations and interviews conducted in 2019 and 2020 with 16 MSM and 10 caregivers in Dakar and Mbour hospitals. The data was subject to a thematic analysis assisted by the software Atlas.Ti.

Results The relationship between MSM and carers is ambiguous. Caregivers are torn between their professional duty to treat MSM and the cost of being stigmatised by other 